\title{
The Gross Clinic - portrett av en pioner
}

\begin{abstract}
Sammendrag
Et av kunsthistoriens mest kjente legeportretter er Thomas Eakins' The Gross Clinic fra 1875. Bildet fikk fornyet aktualitet da det i 2006 ble solgt for 68 millioner dollar til Philadelphia Museum of Art. Vi presenterer her noe av det maleriet kan fortelle oss om kirurgisk praksis i Amerika på den tiden det ble laget. En sammenlikning med et av Eakins' senere legeportretter, The Agnew Clinic (1889), viser at det skjedde mange endringer $\mathrm{i}$ kirurgien på kort tid mot slutten av det 19. århundre. Særlig gjelder dette innen infeksjonsforebygging, anestesi og profesjonsutvikling.
\end{abstract}

Kunsthistorisk har det vært vanlig å sammenlikne The Gross Clinic med gamle mesteres gruppeportretter av kirurger i arbeid på disseksjonssalen. Det mest kjente av disse er Rembrandts Dr. Nicolaes Tulps anatomiforelesning (1632). Etter vår mening er det vel så fruktbart å se Eakins' bilde i sammenheng med samtidige dokumenterende fotografier av medisinsk praksis. Maleriets realistiske motiv ble av samtiden vurdert som uegnet og upassende for et kunstverk. På tross av dette regnet Eakins selv bildet som et av sine beste, og i løpet av det 20. århundre har det fått stadig økt anseelse. The Gross Clinic er i dag det kunstverket som Thomas Eakins først og fremst forbindes med.
Vibeke Cecilie Waallann Hansen

Avdeling samling og utstilling

Nasjonalmuseet for kunst, arkitektur og design

\section{Einar Andreas Sivertsen}

easivertsen@gmail.com

Ortopedisk avdeling

Akershus universitetssykehus

1478 Lørenskog

Thomas Eakins' (1844-1916) maleri The Gross Clinic (1875) portretterer den betydningsfulle amerikanske legen Samuel David Gross (1805-84) i hans virke som kirurg og lærer (fig 1). Portrettet er et hovedverk i Eakins' kunstnerskap og er et av de mest omtalte og studerte amerikanske malerier fra det 19. århundre. Det har ikke alltid hatt denne sentrale posisjonen. Det var først noen tiår etter Eakins' død at bildet ble et yndet forskningsobjekt for både kunsthistorikere og medisinhistorikere.

Bildets sentrale motiv - dr. Gross med skalpellen i en blodig hånd og den avkledde pasienten - møtte sterk motbør i samtiden og skulle vise seg å være en visuell fremstilling som lå for tett opp til virkeligheten for å kunne tekkes den etablerte smak. Eakins presenterte 1870-årenes kunstpublikum for noe ganske nytt i det at han gjenga en faktisk operasjon. En skalpell, blod og naken hud sjokkerer ikke kunstpublikummet i 2009 - med kunnskap om hvordan praksis er i en moderne operasjonsstue reagerer vi på andre elementer i bildet: Fraværet av infeksjonsforebyggende tiltak, den dunkle belysningen og den primitive bedøvelsesmetoden er tre eksempler (1-3). Oppdagelsene gjort i Europa ved Louis Pasteur og Joseph Lister flere år tidligere hadde ikke fått implikasjoner for kirurgisk praksis i Amerika. Dette faktum har gjort at enkelte ser bildet som et bevis på den bakstreverskhet og hybris de mener preget amerikansk kirurgi på denne tiden (4). Det er også blitt fremmet en hypotese om at Eakins hadde til hensikt å fremstille dr. Gross som en mann som var gått ut på dato, en som var arrogant og utdatert i forhold til moderne medisin anno 1875 (4). Vi er uenige i dette - vi velger å tolke bildet ut fra tidens premisser og mener det var Eakins' ambisjon å lage et helteportrett i anledning nasjonens 100-årsjubileum i 1876.

\section{Thomas Eakins}

Thomas Eakins opplevde stor anerkjennelse i sin samtid og hadde en sentral posisjon i amerikansk kunstliv på slutten av 1800tallet. Han var født og vokste opp i Philadelphia, Pennsylvania, der han også bodde og arbeidet mesteparten av sitt liv. Der studerte han, virket som maler og underviste ved Pennsylvania Academy of the Fine Arts.

Mellom 1862 og 1865 studerte han ved akademiet. I denne perioden fulgte han også anatomiforelesninger ved Jefferson Medical College. I 1866 reiste han til datidens hovedscene for billedkunst: Paris. Han ble tatt opp ved École des Beaux-Arts og arbeidet der under Jean-Léon Gérome (1824-1904), senere for en kortere tid under veiledning av portrettmaleren Leon Bonnat (1833-1922).

Eakins' malerier er preget av hans studieopphold i Europa. Men på tross av tre års veiledning fra Gérome er det få direkte synlige spor av denne malerens romantiske og idealiserende stil i bildene. Gérome er kjent for sin detaljorienterte malemåte og sine fremstillinger av historiske og eksotiske motiver. Hans motiver var oftest arrangert i studio, med profesjonelle modeller og kostymer - nøye planlagte komposisjoner. Eakins var i motsetning til dette en konsekvent realist. Hans ambisjon var å male hendelser og menneskene som omga ham. Han var en dyktig fotograf og benyttet ofte fotografier som forelegg for maleriene, og mange av hans bilder tar opp i seg fotografiets øyeblikkskarakter. The Gross Clinic er et godt eksempel på nettopp dette. Vi kommer rett inn i en operasjon: Hudincisjonen er nettopp foretatt, det er blod på skalpellen og hånden til Gross, og en kvinnelig tilskuer, antakelig pasientens mor, holder seg for øynene for å beskytte seg mot synet.

Det er blitt sagt om Eakins' maleriske stil at han kombinerte det han hadde lært av fransk akademitradisjon med spansk barokk, som han for øvrig hadde lært å kjenne hos Leon Bonnat og ved selvstudier i Madrids museer (5). En slik karakterisering av Eakins plasserer ham i fortiden, blant gamle mestere, ikke $\mathrm{i}$ hans egen samtid. Men det som gjør at han har fått en sentral posisjon i amerikansk kunsthistorie, var hans evne til også å fange opp nye ideer om malerkunsten. I hans bilder finner vi en blanding av eldre akademiske prinsipper og nye realistiske tendenser.

Eakins komponerte sine bilder etter tradisjonelle prinsipper. Han skapte romvirkninger ved bruk av sentralperspektiv, og fremstilte personer med utgangspunkt 
i detaljerte anatomikunnskaper. Men med sitt valg av motiver bringer han noe nytt inn i amerikansk maleri. Generelt kan man si om hans motivkrets at den viser personer tilhørende den nye raskt fremvoksende middelklassen, deres profesjoner og fritidssysler. Dette var helt i tråd med motivkretsen til for eksempel hans franske kolleger Edgard Degas, Auguste Renoir og Berthe Morisot og amerikanske Mary Cassatt og deres skildringer av det moderne liv.

The Gross Clinic

Det var maleren selv som tok initiativ til å portrettere dr. Samuel David Gross (6). Eakins var økonomisk uavhengig og kunne fritt male de motiver han ønsket. En stor del av hans produksjon er portretter, men svært få av disse ble utført etter oppdrag. Thomas Eakins portretterte mange leger. Han hadde en høy stjerne blant medisinerne og andre vitenskapsmenn og ble ansett som en dynamisk og innsiktsfull portrettmaler med forståelse for det vitenskapelige miljøet. Eakins følte seg tiltrukket av både kunst og vitenskap. I tillegg til inngående anatomistudier studerte han menneskers og dyrs bevegelsesmønstre, optikk og fotografi.

Den portretterte dr. Gross skriver følgende i sin selvbiografi: «I have performed many operations, and flatter myself that I possess at least some of the qualities of a good operator - a steady hand, an unflinching eye, perfect self-control, and a thorough knowledge of relative anatomy» (7). Kvalifikasjonene en stødig hånd, et uforferdet øye, selvkontroll og god kjennskap til anatomi er det sannsynlig at Eakins også holdt for sentrale for en maler. Han tilnærmet seg malerkunsten på en analytisk måte, og hans mening var at både kunst og vitenskap handlet om å søke sannheten, om å fremstille virkeligheten slik den er (8).

Gross var kjent i Amerika som den mest betydningsfulle kirurg i sin generasjon. Han hadde en ekstraordinær arbeidskapasitet og en stor hengivenhet for sitt arbeid. Han virket som kirurg, forsker og lærer og er kjent som forfatter av en lang rekke verk. Han nøt stor anerkjennelse i sin samtid og er omtalt som «the nestor of American surgery» (9). Dr. Gross var innovativ og oppfant flere kirurgiske instrumenter. På grunn av sin kirurgiske pionerforskning på katter og hunder er han blitt omtalt som «the father of American surgical research (9). Han var professor ved Jefferson Medical College, institusjonen som senere kjøpte Eakins' portrett av ham, fra 1856 til 1882.

I bildet ser vi dr. Gross i et auditorium. Han har akkurat vendt seg bort fra pasienten for å undervise sine studenter. Gross' hode og høyre hånd med den blodige skalpellen samt pasientens lår er bildets sentrale motiv og er fremhevet i sterk belysning. Store deler av maleriet er preget av grove penselstrøk, men kirurgens hånd og skalpellen er utført i en mer nitid maleteknikk. Pasienten

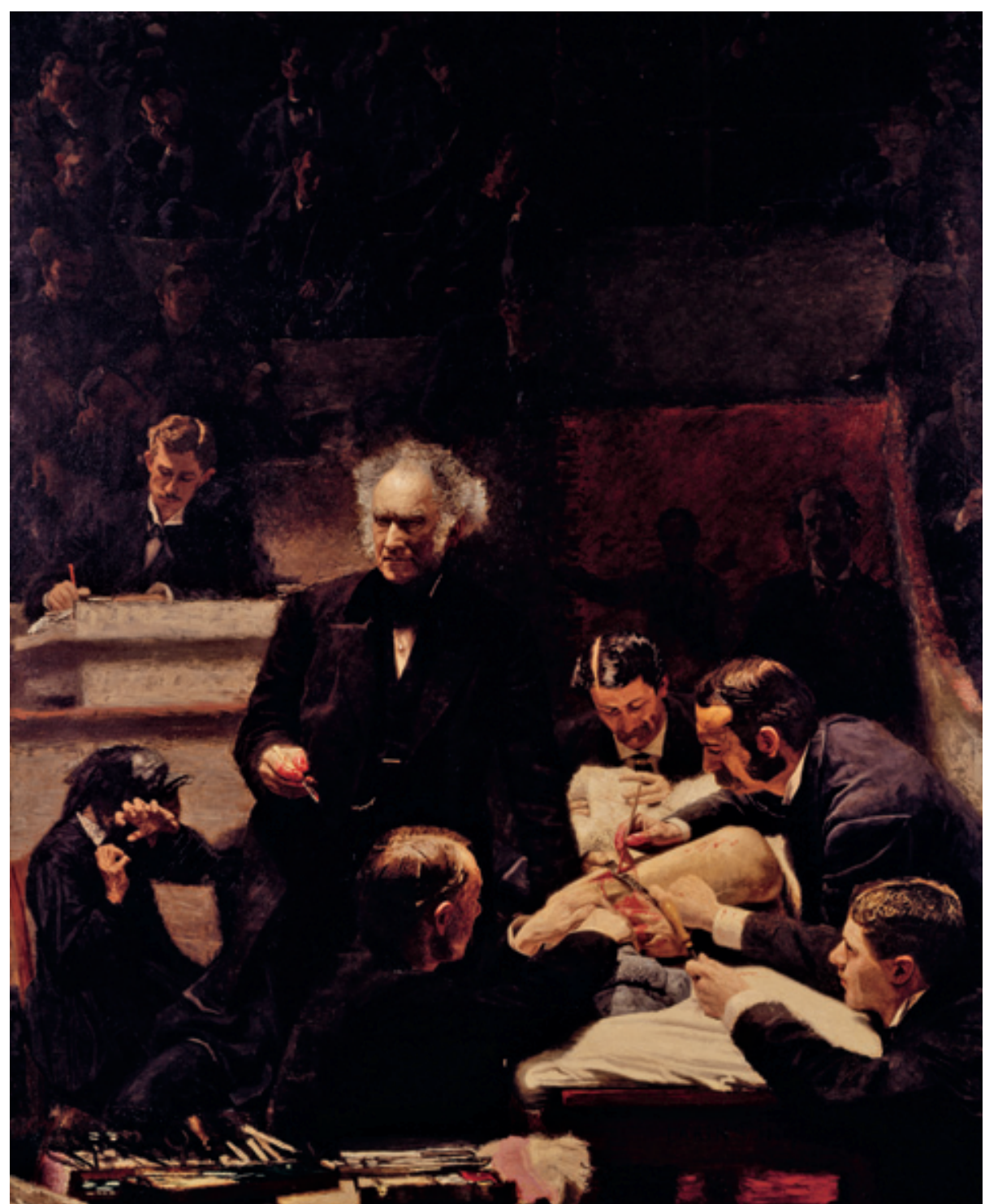

Figur 1 Thomas Eakins, The Gross Clinic, 1875. Olje på lerret, $244 \times 98 \mathrm{~cm}$. Philadelphia Museum of Art and the Pennsylvania Academy of Fine Arts. Foto @ Geoffrey Clements/Corbis/SCANPIX

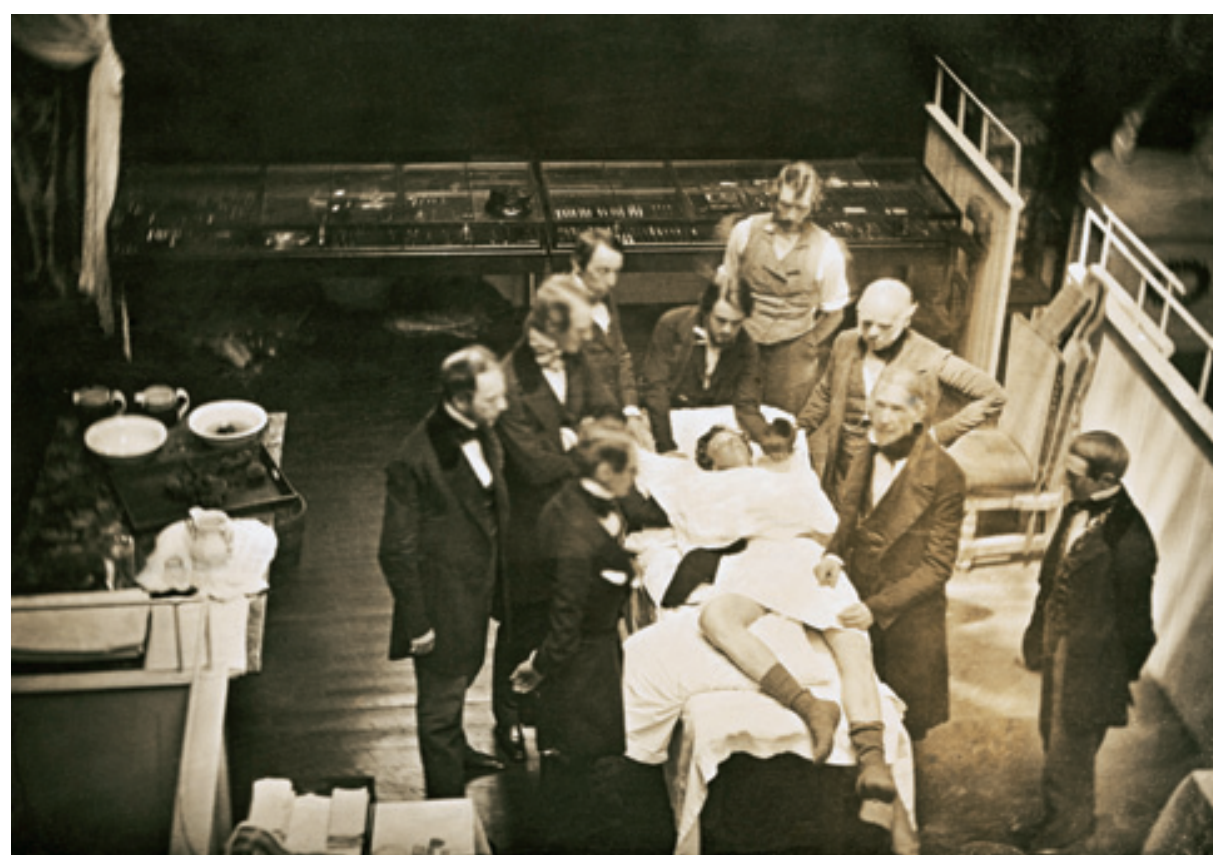

Figur 2 Tidlig operasjon med bruk av eter rundt 1850. Foto @ Bettmann/Corbis/SCANPIX 


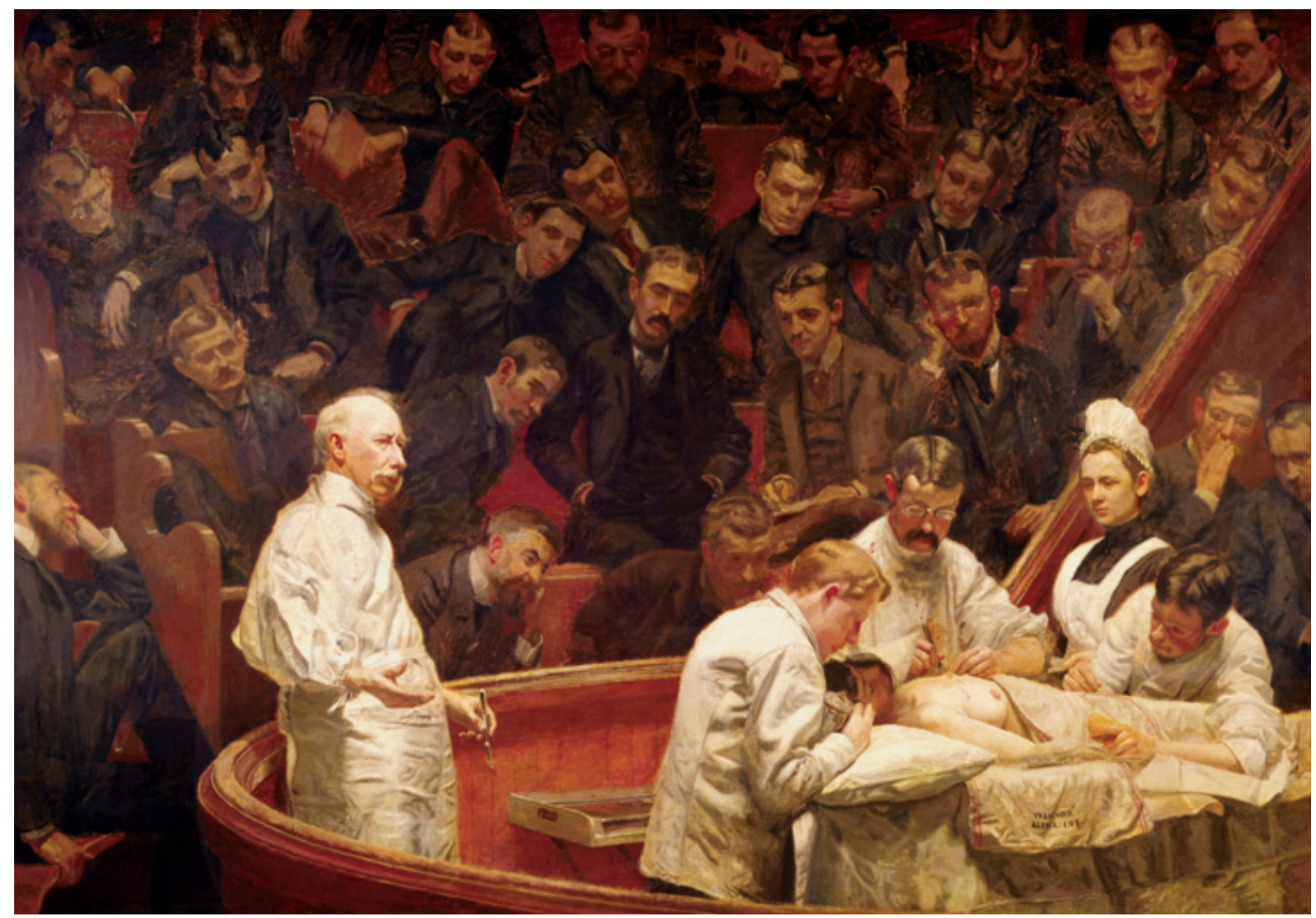

Figur 3 Thomas Eakins, The Agnew Clinic, 1889. Olje på lerret, 214 x $300 \mathrm{~cm}$. University of Pennsylvania, Philadelphia. Foto @ Geoffrey Clement/Corbis/ SCANPIX

ligger på siden med knærne bøyd, og det er gjort en lang incisjon i det venstre låret. En anestesilege og et team på fire kirurger assisterer dr. Gross. Anestesilegen gir pasienten bedøvelsesmiddel på en klut. Både studentene og de fem legene som opererer er fremstilt i svakt lys. Belysningen i bildet er mer eller mindre slik den faktisk var under operasjoner på denne tiden (10). Rundt 20 studenter er å se i bakgrunnen. Valget av avbildet operasjon er ikke tilfeldig. Dr. Gross og hans assistenter fjerner et sekvester fra en pasient med osteomyelitt. Før hans tid var amputasjon eneste behandling for denne lidelsen. Men han hadde utviklet og raffinert en ekstremitetsbevarende teknikk, og han var spesielt kjent for denne type operasjon.

Dr. Gross er avbildet på den kirurgiske arena, i en situasjon der han både er lege og lærer. Eakins' program som portrettmaler var å avbilde vitenskapsmenn og medisinere idet de utførte sitt arbeid (11). Motivet i The Gross Clinic representerte noe nytt og har få forløpere - om noen. En eldre sjanger innen maleriet det er naturlig å sammenlikne med er avbildninger av anatomiundervisning, hvorav det mest kjente er Rembrandts Dr. Nicolaes Tulps anatomifore- lesing fra 1632 (12). Dette trekkes ofte frem til sammenlikning. Et annet og nyere eksempel er F.-N.-A. Feyen-Perrins Dr. Velpeaus anatomiforelesning fra 1864. Men selv om temaet i The Gross Clinic - medisinsk praksis og fremskritt - går helt tilbake til Rembrandts ærverdige fremstilling av leger som dissekerer lik, samsvarer motiv og komposisjon mer med samtidige dokumenterende fotografier av liknende situasjoner (fig 2). Eakins' bilde har en slags vitnekarakter som gjør det naturlig å se det i sammenheng med dokumenterende fotografi. Det realistiske i situasjonen får dominere over eleganse og idealisering. Betrakteren blir i møtet med The Gross Clinic vitne til en virkelig operasjon på et levende menneske. Eakins har malt seg selv inn blant tilskuerne, et bidrag til en bekreftelse på det sanne i situasjonen for oss som betrakter bildet.

I løpet av 1800-tallet utviklet kirurgien seg til et fag med akademisk status. Frankrike var et foregangsland i vitenskapeliggjøringen av faget. I Amerika var Philadelphia et sentrum for utviklingen av legeutdanningen og medisinsk forskning. Byen var også et sentrum for medisinske tidsskrifter. Sannsynligvis ønsket Eakins med The
Gross Clinic å lage et heroisk maleri: Et maleri som fremstilte en av Amerikas fremste leger (10). Hans ambisjon var å delta på the Centennial Exhibition i Philadelphia med portrettet av dr. Gross.

Eakins fikk fem bilder akseptert for visning i kunstgallerier under denne utstillingen i Philadelphia i 1876. The Gross Clinic var ikke et av disse. Bildet ble riktignok vist, men da i en utstilling på et sykehus. Eakins' realistiske gjengivelse av moderne medisin var så uakseptabel at bildet ble oppfattet som en provokasjon i kunstsammenheng. Kritikerne mente det var for realistisk og for direkte i sin skildring av en operasjon og at det virket støtende på dem som så det (13). Eakins selv holdt bildet for å være et av sine beste, men $i$ hans levetid nøt det ikke stor anerkjennelse. Jefferson Medical College kjøpte det i 1878. Statusen som «the greatest painting in American art» har bildet først fått etter Eakins' død i 1916 (7).

\section{Medisinhistorie}

The Gross Clinic ble malt i en tid med store endringer i medisinen, og det er ingen overdrivelse å si at utviklingen har gått fremover siden den gang. Det mest påfallende 
ved bildet i dag er ikke tilstedeværelsen av blod og et nakent lår, men den frapperende mangel på infeksjonsforebyggende tiltak personene i bildet har svart dagligtøy på seg slik at blodet ikke skal synes, pasienten har sokkene på, de kirurgiske instrumentene ligger usystematisk og det er pårørende i operasjonssalen (13). Det er åpenbart at ideen om at mikrober fremkaller infeksjonssykdommer ikke har slått igjennom.

Interessant nok har antiseptikken en lengre historie enn medisinsk mikrobiologi. Ignaz Semmelweis oppdaget i 1847 at grundig håndvask utført mellom obduksjon og forløsning ga færre tilfeller av barselfeber. Han møtte stor motstand og endte sine dager på et mentalsykehus - dødsårsaken var sepsis. I 1867 publiserte Joseph Lister en serie artikler i The Lancet der han redegjorde for hvordan man ved hjelp av ny teknikk kunne kontrollere sårinfeksjoner (14). Han bygde sin metode på Louis Pasteurs oppdagelse om at det er mikrober som fremkaller forråtnelse og gjæring, og overførte dette til medisinen og sårbehandlingen. Lister anbefalte vask av instrumenter og sår med karbolsyre og introduserte således antiseptikken. Han forsto sammenhengen mellom bakterier og puss og kunne slå fast at det ikke var puss $i$ et friskt sår.

Selv om antiseptisk teknikk ble brukt av tyske leger allerede i 1870, tok det tid før Listers ideer fikk gjennomslag i Storbritannia og USA. Kirurgene her var imidlertid godt kjent med forskningen hans, og Lister var den mest prominente utenlandske gjest på den internasjonale medisinske kongress som ble avholdt i Philadelphia i 1876. Her fikk han anledning til å misjonere for antiseptikken. Men det slo dårlig an. Dr. Gross var leder av kongressen og hadde ingen tro på mikrober og antiseptisk teknikk: «Little if any faith is placed by any enlightened or experienced surgeon on this side of the Atlantic in the so-called carbolic acid treatment of Professor Lister,» sa Samuel D. Gross ifølge Lyons \& Petrucellis Medicine: an illustrated history (15).

Det tok altså lengre tid å innføre antiseptisk teknikk i Amerika enn i Europa (16). Det kan ha hatt noe å gjøre med holdningene til premissleverandørene i det amerikanske kirurgiske miljøet. Å opparbeide seg kirurgisk erfaring var krevende. Man måtte tiltrekke seg kunder, og med dødelighetsrater på opptil $50 \%$ pga. postoperative infeksjoner kunne dette være en utfordring. Solide tekniske ferdigheter og sterk selvtillit var nødvendig. Med såpass høye komplikasjonsrater kan det ikke ha vært særlig fristende å gjøre opp kliniske materialer heller. Heller ikke det at Lister viste at det ble betydelig færre postoperative infeksjoner med antiseptisk teknikk var nok til å overbevise tvilerne.

Antiseptikken ble nokså raskt avløst av aseptikken. På Rikshospitalet sørget
Hjalmar Schiøtz i begynnelsen av 1880årene for at legene begynte med hvit frakk og at kirurgiske instrumenter ble kokt før bruk (17). Av denne grunn skal han ha fătt tilnavnet «snobben».

\section{Endringer}

Interessant er det at Eakins 14 år etter The Gross Clinic utførte nok et stort kirurgportrett, The Agnew Clinic (1889) (fig 3). Dette portrettet viser endringen i kirurgisk praksis (18). Oppdraget kom fra en gruppe studenter ved the University of Pennsylvania's School of Medicine som ønsket å hedre den aldrende professor i kirurgi dr. D. Hayes Agnew. I grove trekk er det det samme vi ser i de to portrettene: En kirurg som utfører en operasjon samtidig som han underviser sine studenter. Men påfallende er fraværet av dramatikk i The Agnew Clinic sammenliknet med The Gross Clinic. The Agnew Clinic er utført i horisontalt format og er det største bildet Eakins laget i løpet av sin karriere. Det store formatet og det høye antall studenter og kolleger av dr. Agnew som er med var et valg Eakins selv gjorde. Studentene hadde bestilt et mer beskjedent arbeid, men fikk det mer kompliserte og arbeidskrevende portrettet for samme pris (11). Dette forteller oss at Eakins fortsatt var en ambisiøs portrettmaler.

Det sentrale motivet er her dr. Agnew, som står litt på avstand fra selve operasjonen - det dreier seg om mastektomi på grunn av brystkreft (19). Operasjonen er utført og assistentene er i ferd med å lukke operasjonssåret. Bildet kan ses som et gruppeportrett (hver student kan identifiseres), men lyssettingen av dr. Agnews ansikt gjør at man ikke er i tvil om hvem som spiller hovedrollen. Dr. Agnew hadde en høy stjerne hos sine studenter, og det er nettopp som formidler han portretteres. Skalpellen $i$ venstre hånd viser at han har vært involvert $\mathrm{i}$ operasjonen, men at han har trukket seg ut til siden for å forklare studentene om inngrepet. Hovedtema i dette kirurgportrettet er ikke operasjonen og fjerningen av tumor, men selve undervisningsakten. Dr. Agnew framstår som en formidler, og han har i denne konkrete situasjonen gitt fra seg sin plass til en ny generasjon leger.

Flere elementer i bildet vitner om endringer i kirurgien som har skjedd siden The Gross Clinic ble malt: Antiseptikken har nå fått gjennomslag og legene bærer hvitt tøy under operasjonen. Sykepleierens tilstedeværelse er et annet tegn på den modernisering, profesjonalisering og spesialisering som fant sted i siste halvdel av 1800-tallet.

\section{Prisrekord for et amerikansk portrettmaleri}

The Gross Clinic hadde vært i Thomas Jefferson-universitetets eie siden institusjonen kjøpte det av kunstneren for 200 dollar i 1878. I 2006 tilbød Wal-Martarvingen Alice L. Walton og the National
Gallery of Art i Washington å kjøpe bildet for 68 millioner dollar. Eieren var villig til å selge bildet, men ønsket at det skulle forbli i Philadelphia, tatt i betraktning dets sterke tilknytning til stedet. Philadelphia Museum of Art og Pennsylvania Academy of the Fine Arts fikk derfor muligheten til å kjøpe bildet hvis de kunne matche prisen på 68 millioner dollar innen 45 dager. De to institusjonene fikk i gang en gigantisk pengeinnsamling. Med både store og små bidrag fra over 3000 givere klarte de å samle inn den nødvendige summen, og bildet ble i desember 2006 kjøpt av de to med delt eierskap mellom museet og akademiet. Dette er den høyeste prisen som er gitt for et Eakins-bilde, og er også prisrekord for et amerikansk portrett (20).

Oppgitte interessekonflikter: Ingen

\section{Litteratur}

1. Brieger GH. A portrait of surgery. Surgery in America, 1875-1889. Surg Clin North Am 1987; 67 $1181-216$.

2. Mathiasen $\mathrm{H}$. The heroic physician and The Gross Clinic. Am J Med 2007; 120: $916-7$

3. String ST. Art and commitment. J Vasc Surg 1996; 24: $319-27$

4. Herr HW. Ignorance is bliss: the Listerian revolution and education of American surgeons. J Urol 2007; 177: 457-60.

5. Weinberg HB. Studies in Paris and Spain. I: Sewell D, red. Thomas Eakins. Philadelphia: Philadelphia Museum of Art, 2001: 13-26.

6. Simpson M. The 1870s. I: Sewell D, red. Thomas Eakins. Philadelphia: Philadelphia Museum of Art 2001: 27-40.

7. Fried M. Realism, writing, disfiguration on Thomas Eakins and Stephen Crane. Chicago: University of Chicago Press, 1987.

8. Rosenblum R, Janson HW. 19th-century art. Rev. utg. Upper Saddle River, NJ: Pearson Prentice Hall, 2005

9. Toledo-Pereyra LH. Samuel D. Gross: the nestor of American surgery. J Invest Surg 2006; 19: 141-5.

10. Johns E. Thomas Eakins the heroism of modern life. Princeton, NJ: Princeton University Press، 1983

11. Werbel AB. Thomas Eakins art, medicine, and sexuality in nineteenth-century Philadelphia. New Haven, CT: Yale University Press, 2007.

12. Hove LM, Young S, Schrama JC. Dr. Nicolaes Tulps anatomiforelesning. Tidsskr Nor Legeforen 2008; 128: $716-9$

13. De La Croix H, Tansey RG, Kirkpatrick, D. Gardner's Art through the ages. Orlando, FL: Harcourt Brace \& Company, 1991

14. Lister J. On the antiseptic principle in the practice of surgery. Lancet 1867; 90: 353-6.

15. Lyons AS, Petrucelli RJ. Medicine: an illustrated history. New York: Abradale Press/Abrams, 1987

16. Thurston AJ. Of blood, inflammation and gunshot wounds: the history of the control of sepsis. Aust N Z J Surg 2000; 70: 855-61.

17. Ytteborg J. Hjalmar Schiøtz og hans tonometer. Tidsskr Nor Lægeforen 2001; 121: 464-5

18. Frumovitz MM. Thomas Eakins' Agnew Clinic: a study of medicine through art. Obstet Gynecol 2002; 100: 1296-300.

19. Harris JC. The Agnew Clinic. Arch Gen Psychiatry 2007; 64: 270-1.

20. Kimmelman M. In the company of Eakins. New York Times. www.nytimes.com/2007/01/12/arts/ design/12eaki.html? r=1\&pagewanted=all (6.2.2009).

Manuskriptet ble mottatt 24.10. 2008 og godkjent 12.2. 2009. Medisinsk redaktør Anne Gitte Hertzberg. 